\title{
The Effect of Atorvastatin on Liver Function among Patients with Coronary Heart Disease in Gaza Strip
}

\author{
Mahmmoud H. Taleb" ${ }^{*}$, Ihab M. Almasri², Naima I. Siam³ ${ }^{3}$ Ahmed A. Najim4, Adham I. Ahmed \\ ${ }^{1}$ Department of Pharmacology, Al-Azhar University, Gaza, Palestine \\ ${ }^{2}$ Department of Pharmaceutical Chemistry, Al-Azhar University, Gaza, Palestine \\ ${ }^{3}$ Faculty of Pharmacy, Al-Azhar University, Gaza, Palestine \\ ${ }^{4}$ Faculty of Intermediate Studies, University of Palestine, Gaza, Palestine

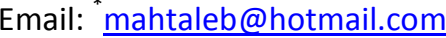

Received 16 April 2014; revised 2 June 2014; accepted 27 June 2014

Copyright (C) 2014 by authors and Scientific Research Publishing Inc.

This work is licensed under the Creative Commons Attribution International License (CC BY).

http://creativecommons.org/licenses/by/4.0/

(c) (i) Open Access

\section{Abstract}

Statins, which are inhibitors of 3-hydroxy-3-methylglutaryl-CoA (HMG-CoA) reductase, are considered as one of the most important drugs and the drug of choice for reducing an abnormal cholesterol level. Statins are normally used to decrease the risk of coronary heart disease (CHD), but they tend to be associated with liver adverse effects. The objective of this prospective study was to investigate the effect of atorvastatin therapy on the liver function in patients with CHD. Study comprised of 66 newly diagnosed CHD patients who were selected from UNRWA clinics in the Gaza Strip. The patients were clinically examined and treated with atorvastatin $(10-40 \mathrm{mg} / \mathrm{day})$. A questionnaire was used to collect the data concerning patient's characteristics. Total cholesterol (TC), triglycerides (TG), high density lipoprotein cholesterol (HDL-C), low-density lipoprotein cholesterol (LDL-C), liver enzymes tests such as alanine aminotransferase (ALT) and aspartate aminotransferase (AST) and total and direct blood bilirubin were measured before starting treatment and after 3 and 6 months of treatment. The results showed a significant increase in the mean values of ALT, AST, total bilirubin and direct bilirubin levels after 3 months then decreased after the next 3 months, but they were higher than the baseline with insignificant association.

\section{Keywords}

Statins, Atorvastatin, Coronary Heart Disease, Liver Transaminases

\footnotetext{
*Corresponding author.
} 


\section{Introduction}

Coronary heart disease (CHD) is the principle cause of morbidity and mortality worldwide [1]. The main cause of CHD is atherosclerosis that develops in the arteries that encircle the heart and supply it with blood [2].

Many studies have proved the link between coronary heart disease and cholesterol. Framingham Study which is one of the first studies showed a direct link between high blood cholesterol levels and development of CHD. It showed a link between other risk factors, such as hypertension, cigarette smoking, male gender, family history, and age, with CHD development [3].

Dietary modification would reduce the levels of blood cholesterol by $10 \%-20 \%$, but for further reduction, cholesterol lowering drugs are usually required. The most recent drugs developed for this purpose are statins or 3-hydroxy-3-methyglutaryl coenzyme A reductase inhibitors which used for prevention and treatment of CHD; they lower cholesterol levels by $20 \%$ - 30\%, and even more at higher doses, and this has been clinically proven to produce an equivalent decrease in the risk of myocardial infarction and death [4]. Statins have become one of the best-selling medication classes to date since their introduction into the marketplace in 1986, and include the following drugs commercially available in the US: atorvastatin, lovastatin, pravastatin, fluvastatin, simvastatin and rosuvastatin [5]. Statins are highly effective in reducing cardiovascular mortality and are widely prescribed with best selling. More than 145 million prescriptions were written for statins in the US in 2005, including atorvastatin, the best selling prescription drug in the world [6] [7].

Statins considered the drugs of first choice for modifying lipid risk factors for CHD, in addition to reversible inhibition of hydroxymethylglutaryl coenzyme A (HMG-CoA) reductase. They have an ability to produce large reductions in low-density lipoprotein cholesterol (LDL-C) and ability to increase HDL cholesterol (HDL-C) [8] [9]. Statins like all medications, have potential adverse effects. The most serious are liver and muscle adverse effects. Cognitive loss, neuropathy, sexual dysfunction and, pancreatic dysfunction are examples of other adverse effects [7].

Hepatic dysfunction includes either liver enzymes elevations as a result of liver injury or liver function disturbances. The last two were studied according to the current guidelines which recommend measuring transaminases (ALT $=$ alanine aminotransferase, AST $=$ aspartate aminotransferase) levels before initiating therapy. 12 weeks after starting therapy, signs of potential hepatotoxicity such as jaundice, malaise, fatigue, and lethargy should alert physicians to measure transaminase levels and liver function tests. Fractionated bilirubin levels are recommended to rule out hepatic injury [10].

Abnormal hepatic transaminase levels are recognized as an infrequent occurrence of statin therapy. In particular, the transaminases seem to increase within the first 3 and 6 months of therapy [11]. In the majority of clinical trials, elevated ALT levels three times greater than the upper limit of normal on two or more measurements have been considered as a safety endpoint. It was found that $1 \%$ of patients receiving low to intermediate statins dose (10 - $40 \mathrm{mg}$ daily ) and in $2 \%$ - 3\% of patients on high dose therapy (80 mg/daily) ALT elevation occurs [12].

Because of the absence of data concerning the hepatic toxicity of statins in Palestine, the present study was performed to evaluate the hepatic adverse effects of statins by measuring the serum ALT, AST activities and serum direct and total bilirubin concentration in a number of newly diagnosed patients with CHD.

\section{Subjects and Methods}

\subsection{Study Design and Patient Population}

This study was undertaken over a period of 6 months from November 2010 till July 2011 in UNRWA health centers in Gaza Strip-Palestine. Ethical approval was obtained from the UNRWA and Helisinki committee in the Ministry of Health.

\subsection{Sample and Sampling}

Sixty six patients were newly diagnosed with CHD participated in the study, 37 males and 29 females, the mean age of both males and females was between $55 \pm 10.3$ years. The Patients were treated with atorvastatin at therapeutic dose with a range of (10 - 40) mg daily once a day at bedtime according to cardiologist assessment.

\subsection{Inclusion Criteria}

1) Newly diagnosed patients with CHD. 
2) Patients with normal liver functions and liver enzymes.

3) Patients with abnormal liver functions and liver enzymes were excluded from the study.

4) Patients with hepatitis B \& $C$ or any liver diseases or any disease which may cause alteration of liver function tests were excluded from the study. This may be aided by taking history, and physical and clinical examination of the patients

5) Patients on continuous administration of statins treatment or other lipid lowering agents were also excluded from the study.

6) Patients receiving other medications affecting liver functions or liver enzymes.

\subsection{Tools of the Study}

Patient's data were collected from the medical record, an interview questionnaire and clinical examination. Colorimetric methods were used for determination of total cholesterol [13], TG [14], HDL-C, LDL-C [15]. Photometric colorimetric methods were used for determination of ALT, AST, and total and direct blood bilirubin.

\subsection{Statistical Design}

Data were analyzed using the statistical package for social science (SPSS) computer program version 16. Descriptive statistics were performed to describe all variables. Chi-square was used to investigate the association between the study variables. Paired T-test was used to study the differences between the variables means. The significant of the association was tested at an alpha level of $P<0.05$.

\section{Study Results}

\subsection{Patient Characteristics}

The patient characteristics, family history and lipid parameters are listed in Table 1. Fifty six percent of patients were with heart disease family history. Forty three percent of patients were smokers. Fifty seven percent were obese. All the participants were treated with atorvastatin $(10-40 \mathrm{mg})$ with the majority (83\%) were receiving a daily dose of $20 \mathrm{mg}$.

Table 1. Patient characteristics and lipid parameters $(n=66)$.

\begin{tabular}{|c|c|}
\hline Patient characteristics & All patients $(\mathrm{n}=66)$ \\
\hline Male & $56.1 \%$ \\
\hline Female & $43.9 \%$ \\
\hline Age (years) [mean \pm SD] & $55 \pm 10.3$ \\
\hline Family history of heart disease (\%) & 56.1 \\
\hline Current smokers (\%) & 43.9 \\
\hline Systolic BP $(\mathrm{mmHg})[$ mean $\pm \mathrm{SD}]$ & $131.8 \pm 13.5$ \\
\hline Diastolic BP (mmHg) [mean \pm SD] & $80.3 .0 \pm 8.2$ \\
\hline BMI $s\left(\mathrm{~kg} / \mathrm{m}^{2}\right)[$ mean $\pm \mathrm{SD}]$ & $30.9 \pm 5.8$ \\
\hline $\mathrm{BMI}>30 \mathrm{~kg} / \mathrm{m}^{2}(\%)$ & 57.6 \\
\hline \multicolumn{2}{|l|}{ Lipid parameters } \\
\hline High total cholesterol (mg/dL) (\%) & 15.1 \\
\hline High LDL-C (mg/dL) (\%) & 13.6 \\
\hline High HDL-C (mg/dL) (\%) & 13.6 \\
\hline High triglycerides (mg/dL) (\%) & 15 \\
\hline \multicolumn{2}{|l|}{ Atorvastatin dose } \\
\hline 10 mg (\%) & 14 \\
\hline 20 mg (\%) & 83 \\
\hline $40 \mathrm{mg}(\%)$ & 3 \\
\hline \multicolumn{2}{|l|}{ Drug Interaction } \\
\hline \multicolumn{2}{|l|}{ Diltiazem } \\
\hline \multicolumn{2}{|c|}{$\begin{array}{l}\text { fBMI = body mass Index } \\
\text { *The classification according to NCEP [16], all the values are mg/dL. }\end{array}$} \\
\hline
\end{tabular}




\subsection{The Effect of Statins on Liver Function}

\subsubsection{Distribution of Study Population by the Liver Transaminases and Bilirubin}

According to the data shown in Table 2, 98.5\% of the study population was within the normal ALT range. This percent decreased after 3 months to $81.8 \%$ and accordingly, 18.2\% of the patients have abnormal values of ALT. On the other hand, all the patients had normal values of AST at the baseline. However, the percent of patients with abnormal high AST levels increased to $9.1 \%$ at the first three months of the study and then decreased to $3 \%$ after 6 months. Similarly, the percent of abnormal total and direct bilirubin increased in the first three months and then decreased at the last three months of the study period.

\subsubsection{The Effect of Statins on Liver Function and Liver Enzymes}

\section{1) The effect of statins on liver transaminases}

Results shown in Table 3 indicated a significant increase in the mean values of ALT and AST levels after 3 months of statins treatment compared to pre-treatment values. The new attainable levels of ALT and AST after 6 months of treatment were higher than the baseline levels; however, they were statistically insignificant.

\section{2) The effect of statins on bilirubin}

The data shown in Table 4 pointed out a significant increase in the mean values of total and direct bilirubin after 3 months of statins treatment compared to pretreatment values. The new attainable levels of bilirubin after 6 months were higher than the baseline levels, however, they were statistically insignificant $(p>0.05)$.

\section{Disscussion}

\subsection{The Relationship between Statins and Aminotransferases}

The results of the current study revealed a mild to moderate asymptomatic but statistically significant elevations

Table 2. Distribution of study population by the liver transaminases and bilirubin variables $(\mathrm{n}=66)$.

\begin{tabular}{|c|c|c|c|c|c|c|c|}
\hline \multirow{2}{*}{\multicolumn{2}{|c|}{ Variable }} & \multicolumn{2}{|c|}{ Baseline } & \multicolumn{2}{|c|}{ After 3 Months } & \multicolumn{2}{|c|}{ After 6 Months } \\
\hline & & Number & $(\%)$ & Number & (\%) & Number & $(\%)$ \\
\hline \multirow{2}{*}{ ALT } & Normal & 65 & 98.5 & 54 & 81.8 & 61 & 92.4 \\
\hline & Abnormal & 1 & 1.5 & 12 & 18.2 & 5 & 7.6 \\
\hline \multirow{2}{*}{ AST } & Normal & 66 & 100 & 60 & 90.9 & 64 & 97.0 \\
\hline & Abnormal & - & - & 6 & 9.1 & 2 & 3 \\
\hline \multirow{2}{*}{ Total bilirubin } & Normal & 66 & 100 & 61 & 92.4 & 64 & 97.0 \\
\hline & Abnormal & - & - & 5 & 7.6 & 2 & 3.0 \\
\hline \multirow{2}{*}{ Direct bilirubin } & Normal & 64 & 97.0 & 63 & 95.5 & 64 & 97.0 \\
\hline & Abnormal & 2 & 3 & 3 & 4.5 & 2 & 3 \\
\hline
\end{tabular}

Table 3. Levels of liver enzymes ALT, AST (U/L) before and at 3 and 6 months during the study period $(n=66)$.

\begin{tabular}{|c|c|c|c|c|c|c|}
\hline Variable & Time & Number & Mean & SD & t-test & p-value \\
\hline \multirow{3}{*}{ ALT } & Before Atorvastatin & 66 & 18.95 & 7.28 & -4.3 & $0.00^{\mathrm{a}}$ \\
\hline & After 3 months of Atorvastatin & 66 & 26.95 & 14.43 & -1.7 & $0.09^{\mathrm{b}}$ \\
\hline & After 6 months of Atorvastatin & 66 & 21.36 & 10.28 & 2.8 & $0.006^{\mathrm{c}}$ \\
\hline \multirow{3}{*}{ AST } & Before Statins & 66 & 18.61 & 6.305 & -3.113 & $0.00^{\mathrm{a}}$ \\
\hline & After 3 months of Statins & 66 & 24.85 & 12.329 & -4.884 & $0.171^{\mathrm{b}}$ \\
\hline & After 6 months of Statins & 66 & 20.61 & 9.915 & 0.978 & $0.012^{c}$ \\
\hline
\end{tabular}

${ }^{\mathrm{a}}$ Difference of means between before Atorvastatin and 3 months after Atorvastatin; ${ }^{\mathrm{b}}$ Difference of means between before Atorvastatin and 6 months after Atorvastatin; ${ }^{\mathrm{C}}$ Difference of means between 3 months after Atorvastatin and 6 months after Atorvastatin. 
Table 4. Levels of total and direct bilirubin for the patients before and at 3 and 6 months during study period $(n=66)$.

\begin{tabular}{clcccccc}
\hline \multicolumn{1}{c}{ Variable } & \multicolumn{1}{c}{ Time } & Number & Mean & SD & t-test & p-value \\
\hline \multirow{3}{*}{ Total Bilirubin } & Before Atorvastatin & 66 & 0.659 & 0.218 & -4.948 & $0.00^{\mathrm{a}}$ \\
& After 3 months of Atorvastatin & 66 & 0.796 & 0.246 & -1.054 & $0.296^{\mathrm{b}}$ \\
& After 6 months of Atorvastatin & 66 & 0.699 & 0.211 & 2.543 & $0.013^{\mathrm{c}}$ \\
& Before Atorvastatin & 66 & 0.227 & 0.137 & -2.115 & $0.038^{\mathrm{a}}$ \\
& After 3 months of Atorvastatin & 66 & 0.297 & 0.249 & -1.767 & $0.082^{\mathrm{b}}$ \\
& After 6 months of Atorvastatin & 66 & 0.265 & 0.135 & 1.237 & $0.221^{\mathrm{c}}$ \\
\hline
\end{tabular}

${ }^{\mathrm{a}}$ Difference of means between before statins and 3 months after atorvastatin; ${ }^{\mathrm{b}}$ Difference of means between before statins and 6 months after atorvastatin; ${ }^{\mathrm{C}}$ Difference of means between 3 months after statins and 6 months after atorvastatin.

of aminotransferases exceeding $1 \mathrm{X}$ upper normal limits (UNL). However, no case was with severe elevation higher than 3X UNL was found. This elevation can be identified as "transaminitis" in which liver enzyme levels are elevated in the absence of proven hepatotoxicity [17]. Furthermore, the obtained results showed a significant increase in the mean values of ALT levels after 3 and 6 months of statins treatment compared to pre-treatment values. On the other hand, the mean values of AST increased significantly only at the first 3 months post-statins treatment compared to the pre-treatment values $(p<0.001)$ and then decreased back to an insignificant level $(20.61 \pm 9.915 \mathrm{U} / \mathrm{L})$ at the last three months. This difference between the ALT and AST elevation, post-statin treatment, may be related to the higher sensitivity of ALT to hepatic inflammation [18].

The results obtained were similar to the results found in a study provided by Chang \& Schiano [19] who declared that generally mild aminotransferases elevation associated with statin occurs within the first 12 weeks and is asymptomatic and improves spontaneously. The incidence ranges from $0 \%$ to $3 \%$. Similarly, another study conducted by Al-Jubori \& Mahmood [20] demonstrated a mild elevation of ALT and AST activities less than 3 $\mathrm{X}$ the UNL post-statin treatments. On the other hand, several studies reported higher elevation values of ALT and AST activities more than 3X UNL [21]-[23]. Furthermore, several clinical cases of autoimmune hepatitis an acute cholestatic hepatitis were reported after atorvastatin treatment [24].

Castro [25] reported another case of 72 years-old man who developed acute cholestatic hepatitis after atorvastatin treatment at a higher dose than lower doses. After treatment discontinuation, the patient made a full recovery. Elevations of all measured hepatic parameters in the current study were observed. This may indicate that the pattern of hepatotoxicity caused by atorvastatin is a mixed pattern of liver damage and hepatocellular damage [6].

Review of literature revealed varied periods of therapy at which the hepatic effect of statins was detected; 3 and 6 months [11]; 4 months [26]; 2 - 4 times during the first year of treatment and 1 - 2 times per year subsequently [27].

The mechanisms behind these adverse effects are unclear, but a few possibilities have been suggested. It has been noted that statins can induce a transient acute phase response on initiation, especially at high doses [28] [29] and this may represent a transient chemical hepatitis due to disturbance of the cholesterol-bile acid pathways [30]. Moreover, it was speculated that the increased transaminases serum activity reflects alterations to the hepatocellular membrane (e.g., enhanced permeability) that permit leakage of these intracellular proteins [21]. The former mechanisms appear to be a pharmacodynamic effects rather than a representation of cellular and particularly liver toxicity [31].

\subsection{The Relationship between Statins and Bilirubin}

The published data on the effect of statins on bilirubin are rare in comparison with articles related to the effect of statins on liver transaminases. Some studies assessed total bilirubin [17]. As one of the liver parameters; some assessed fractioned bilirubin [12] and others assessed both [32]. Since 2001, a total bilirubin level of more than 2X UNL has been used in combination to transaminases to define clinically-significant abnormal liver function, with confirmation required by additional clinical and laboratory data [33]. One case of a 68 years old man was on atorvastatin $20 \mathrm{mg} /$ day, showed abnormal elevation in both total and direct bilirubin which was 7.4 and 4.5 
$\mathrm{mg} / \mathrm{dl}$ respectively in addition to transaminitis [32].

In this study both total and direct bilirubin were measured and the relationship between them and statins treatment were analyzed. According to the results obtained, there was a significant increase in the mean values of total bilirubin in the first 3 months of study period increased from $(0.659 \pm 0.2179 \mathrm{mg} / \mathrm{dL})$ to $(0.796 \pm 0.2461$ $\mathrm{mg} / \mathrm{dL})$, at $(p<0.01)$. This is similar to the results obtained in a previous study in which patients on simavastatin and lovastatin (10 - $20 \mathrm{mg}$ ) showed statistically significant elevation in the total bilirubin level [20]. On the other hand, there was a mild increase, however, statistically insignificant, in the direct bilirubin mean value after 3 and 6 months of atorvastatin treatment. This insignificant relation may be due to the antioxidant effect of statins which is one of the most important of statins pleiotropic properties; a recent study on mice administered statins showed that statins increase the plasma antioxidant level [34].

Statins have also been reported to up-regulate antioxidant enzymes: catalase, superoxide dismutase and glutathione peroxidase, which eliminate free radicals by the generation of water and oxygen [35]-[37]. Thus that might be related to the short term of period of the study and the small sample size.

\subsection{Some Risk Factors for Statins Liver Adverse Effects}

The incidence of statins-induced hepatotoxicity is uncommon events and the reported incidence is very low [38]. The incidence of statin-induced liver injury may increase because of the presence other risk factors which could increase patient liver-injury susceptibility. Three risk factors (obesity, dose, drug interaction) were studied.

Several studies showed that obese individuals may have higher levels of serum transaminases than their lean counterparts [39]. However; other studies concluded that the administration of statins to obese patients seems to be equally safe with the use of these drugs in lean subjects [40].

The results of the current study show that there was no significant relationship between liver enzyme elevation and the dose of statins. This was in agreement of Shepherd [41]. And it was different from other studies that indicate that the enzymes and bilirubin emerge with higher doses. The results of this study may be not real due to that no high dose $(80 \mathrm{mg})$ was administered from any of the patients, such $(10,20,40 \mathrm{mg})$ doses which were available in the study were classified as low and moderate doses respectively [42] [43].

Shepherd [44] found that the rate of liver enzyme elevation with atorvastatin $80 \mathrm{mg} / \mathrm{dL}$ was four times greater compared with atorvastatin $10 \mathrm{mg} / \mathrm{dL}$. Thus, hepatotoxic effects were related to the drug and dose used. Bhardwaj \& Chalasani [6] also found that higher doses leading to greater frequency of transminases elevations and described it a dose-related phenomenon. The results of this study might be different to the new studies due to the range of doses used (10 - $40 \mathrm{mg}$ ) is considered a low to moderate dose, no patient was on higher doses (80 mg).

In our study, the selected patients were asked about the most common drugs that interact with atorvastatin. The results showed that there was no drug interaction between these drugs and atorvastatin except diltiazem. There was a significant relationship between diltiazem co-administered with statins and transminitis. This result was similar to Law \& Rudnicka [45] who reported that diltiazem increases the plasma levels of statins, and may lead to statin-related adverse effects. Gladding [46] found that the toxicity of statins metabolized by cytochrome P450 3A4, such as simvastatin and atorvastatin, is enhanced when the drugs are prescribed in high doses with diltiazem.

\section{Conclusion}

In conclusion, the effects of atorvastatin on both blood tranaminases and bilirubin levels support the previous findings of potential statin hepatotoxicity. Therefore, the FDA labeling information for all statins recommends liver function testing before putting a patient on a statins, 12 weeks after initiation, at any dose increase, and "periodically" for long-term maintenance therapy. These recommendations are based on expert opinion only, because most data suggest that significant liver damage from statins is very rare and that routine monitoring of liver enzymes is not necessary. The ACC/AHA/NHLBI Clinical Advisory on the Use and Safety of Statins agrees with the FDA, although it specifies "periodically" to mean annually [47].

\section{References}

[1] Ludman, A., Venugopal, V., Yellon, D., et al. (2009) Statins and Cardioprotection-More than Just Lipid Lowering? Pharmacology \& Therapeutics, 122, 30-43. http://dx.doi.org/10.1016/j.pharmthera.2009.01.002

[2] Hurst, M. (2008) Hurst Reviews, Pathophysiology Review. 1st Edition, McGraw-Hill, New York, 194-199. 
[3] Torpy, J., Burke, A. and Glass, R. (2009) Coronary Heart Disease Risk Factors. JAMA, 302, 2388. http://dx.doi.org/10.1001/jama.302.21.2388

[4] White, F. and Wang, L. (2006) Statins and Coronary Artery Disease. The Internet Journal of Cardiovascular Research, 3.

[5] Kapur, N. and Musunuru, K. (2008) Clinical Efficacy and Safety of Statins in Managing Cardiovascular Risk. Journal of Vascular Health and Risk Management, 2, 341-353.

[6] Bhardwaj, S. and Chalasani, N. (2007) Lipid Lowering Agents That Cause Drug-Induced Hepatotoxicity. Clinics in Liver Disease, 11, 597-613. http://dx.doi.org/10.1016/j.cld.2007.06.010

[7] Golomb, B. and Evans, M. (2008) Statin Adverse Effects A Review of the Literature and Evidence for a Mitochondrial Mechanism. American Journal of Cardiovascular Drugs, 8, 373-418. http://dx.doi.org/10.2165/0129784-200808060-00004

[8] Mckenney, J. (2003) Pharmacologic Characteristics of Statins. Clinical Cardiology, 26, 32-38. http://dx.doi.org/10.1002/clc.4960261507

[9] Thadani1, U. (2009) Treatment with Statins in High-Risk Patients: Relevance of Time to Titration of Dose and Adverse Outcomes. American Journal of Cardiovascular Drugs, 3, 211-212.

[10] Chalasani, N. (2005). Statins and Hepatotoxicity: Focus on Patients with Fatty Liver. Hepatology, 41, 690-695. http://dx.doi.org/10.1002/hep.20671

[11] Armitage, J. (2007) The Safety of Statins in Clinical Practice. Lancet, 370, 1781-1790. http://dx.doi.org/10.1016/S0140-6736(07)60716-8

[12] Cohen, D., Anania, F. and Chalasani, N. (2006) An Assessment of Statin Safety by Hepatologists. American Journal of Cardiology, 97, S77-S81. http://dx.doi.org/10.1016/j.amjcard.2005.12.014

[13] Deeg, R. and Ziegenhorn, J. (1983) Kinetic Enzymatic Method for Automated Determination of Total Cholesterol in Serum. Clinical Chemistry, 29, 1798-1802.

[14] Friedewald, W.T., Levy, R.I. and Fredrickson, D.S. (1972) Estimation of the Concentration of Low-Density Lipoprotein Cholesterol in Plasma, without Use of the Preparative Ultracentrifuge. Clinical Chemistry, 18, 499-502.

[15] Lopes-Virella, M., Stone, P., Ellis, S. and Colwell, J. (1977) High Density Lipoprotein and Low Density Lipoproteins. Clinical Chemistry, 23, 882.

[16] National Cholesterol Education Program (NCEP), Third Report (2002) Expert Panel on Detection, Evaluation, and Treatment of High Blood Cholesterol in Adults (Adult Treatment Panel III) Final Report. Circulation, 106, 3143-3421.

[17] Calderon, R.M., Cubeddu, L.X., Goldberg, R.B. and Schiff, E.R. (2010) Statins in the Treatment of Dyslipidemia in the Presence of Elevated Liver Aminotransferase Levels: A Therapeutic Dilemma. Mayo Clinic Proceedings, 85, 349356. http://dx.doi.org/10.4065/mcp.2009.0365

[18] Fraser, A. (2002) Interpretation of Liver Enzyme Tests-A Rapid Guide. Zealand Family Physician Journal, 29, 117120.

[19] Chang, C.Y. and Schiano, T.D. (2007) Review Article: Drug Hepatotoxicity. Alimentary Pharmacology \& Therapeutics, 25, 1135-1151. http://dx.doi.org/10.1111/j.1365-2036.2007.03307.x

[20] Al-Jubori, Z. and Mahmood, I. (2007) Comparative Effects of Lovastatin and Simvastatin on Liver Function Tests in Hyperlipdaemic Patients. The Medical Journal of Basrah University, 25, 19-24.

[21] Tolman, K. (2002) The Liver and Lovastatin. American Journal of Cardiology, 89, 1374-1380. http://dx.doi.org/10.1016/S0002-9149(02)02355-X

[22] Buse, J. (2003) Statin Treatment in Diabetes Mellitus. Clinical Diabetes, 21, 168-172. http://dx.doi.org/10.2337/diaclin.21.4.168

[23] Gotto, A.M. (2003) Safety and Statin Therapy: Reconsidering the Risk and Benefits. JAMA Internal Medicine, 163, 657-659. http://dx.doi.org/10.1001/archinte.163.6.657

[24] Pelli, N., Setti, M., Cella, P., Toncini, C. and Indiveri, F. (2003) Autoimmune Hepatitis Revealed by Atorvastatin. European Journal of Gastroenterology \& Hepatology, 15, 921-924.

[25] Castro, M., Hermo, J., Baz, A., Luaces, C., Perez, R. and Clofent, J. (2006) Acute Cholestatic Hepatitis after Atorvastatin Reintroduction. Gastroenterología y Hepatología, 29, 21-24.

[26] Angulo, P. (2002) Nonalcoholic Fatty Liver Disease. New England Journal of Medicine, 346, 1221-1231. http://dx.doi.org/10.1056/NEJMra011775

[27] Bernini, F., Poli, A. and Paoletti, R. (2001) Safety of HMG-CoA Reductase Inhibitors: Focus on Atorvastatin. Cardiovascular Drugs and Therapy, 15, 211-218. http://dx.doi.org/10.1023/A:1011908004965

[28] Wierzbicki, A., Lumb, P., Semra, Y. and Crook, M. (1998) Effect of Atorvastatin on Plasma Fibrinogen. Lancet, 351, 
569-570. http://dx.doi.org/10.1016/S0140-6736(05)78556-1

[29] Wierzbicki, A., Lumb, P. and Chik, G. (2001) Comparison of Therapy with Simvastatin 80 mg and 120 mg in Patients with Familial Hypercholesterolaemia. International Journal of Clinical Practice, 55, 673-675.

[30] Wierzbicki, A., Poston, R. and Ferro, A. (2003) The Lipid and Non-Lipid Effects of Statins. Pharmacology \& Therapeutics, 99, 95-112. http://dx.doi.org/10.1016/S0163-7258(03)00055-X

[31] Macdonald, J. and Halleck, M. (2004) The Toxicology of HMG-CoA Reductase Inhibitors: Prediction of Human Risk. Toxicologic Pathology, 32, 26-41. http://dx.doi.org/10.1080/01926230490462057

[32] Minha, S., Golzman, G., Adar, I. and Rapoport, M. (2009) Cholestatic Jaundice Induced by Atorvastatin: A Possible Association with Antimitochondrial Antibodies. Israel Medical Association Journal, 11, 440-441.

[33] CDER-PH RMA, AASLD Conference (2000) Clinical White Paper on Drug-Induced Hepatotoxicity.

[34] Ahmed, A. and Cudmore, M. (2009) Can the Biology of VEGF and Haem Oxygenases Help Solve Pre-Eclampsia? Molecular and Cellular Mechanisms of Angiogenesis. Biochemical Society Transactions, 37, 1237-1242. http://dx.doi.org/10.1042/BST0371237

[35] Wassmann, S., Laufs, U., Baumer, A., Muller, K., Ahlbory, K., Linz, W., et al. (2001) HMG-CoA Reductase Inhibitors Improve Endothelial Dysfunction in Normocholesterolemic Hypertension via Reduced Production of Reactive Oxygen Species. Hypertension, 37, 1450-1457. http://dx.doi.org/10.1161/01.HYP.37.6.1450

[36] Wassmann, S., Laufs, U., Muller, K., Konkol, C., Ahlbory, K., Baumer, A., et al. (2002) Cellular Antioxidant Effects of Atorvastatin in Vitro and in Vivo. Arteriosclerosis, Thrombosis, and Vascular Biology, 22, 300-305. http://dx.doi.org/10.1161/hq0202.104081

[37] Perez-Guerrero, C., De Sotomayor, M., Jimenez, L., Herrera, M. and Marhuenda, E. (2003) Effects of Simvuastatin on Endothelial Function after Chronic Inhibition of Nitric Oxide Synthase by L-NAME. Journal of Cardiovascular Pharmacology, 42, 204-210. http://dx.doi.org/10.1097/00005344-200308000-00008

[38] Larrey, D. (2002) Epidemiology and Individual Susceptibility to Adverse Drug Reactions Affecting the Liver. Seminars in Liver Disease, 22, 145-155. http://dx.doi.org/10.1055/s-2002-30101

[39] Sheth, S., Gordon, F. and Chopra, S. (1997) Nonalcoholic Steatohepatitis. Annals of Internal Medicine, 126, $137-145$. http://dx.doi.org/10.7326/0003-4819-126-2-199701150-00008

[40] Kiortsis, D., Nikas, S., Hatzidimou, K., Tsianos, E. and Elisaf, M.S. (2003) Lipid-Lowering Drugs and Serum Liver Enzymes: The Effects of Body Weight and Baseline Enzyme Levels. Fundamental \& Clinical Pharmacology, 17, 491494. http://dx.doi.org/10.1046/j.1472-8206.2003.00176.x

[41] Shepherd, J., Cobb, S., Ford, I., et al. (1995) Fibrates and Statins in the Treatment of Hyperlipidemia: An Appraisal of Their Efficacy and Safety. European Journal of Cardiology, 16, 5-13.

[42] Ballantyne, C., Blazing, M., Hunninghake, D., Davidson, M.H., Yuan, Z., DeLucca, P., Ramsey, K.E., Hustad, C.M. and Palmisano, J. (2003) Effect on High-Density Lipoprotein Cholesterol of Maximum Dose Simvastatin and Atorvastatin in Patients with Hypercholesterolemia: Results of the Comparative HDL Efficacy and Safety Study (CHESS). American Heart Journal, 146, 862-869. http://dx.doi.org/10.1016/S0002-8703(03)00440-X

[43] Illingworth, D., Crouse, J., Hunninghake, D., Davidson, M.H., Escobar, I.D., Stalenhoef, A.F., et al. (2001) A Comparison of Simvastatin and Atorvastatin up to Maximal Recommended Doses in a Large Multicenter Randomized Clinical Trial. Current Medical Research and Opinion, 17, 43-50.

[44] Shepherd, J., Blauw, G., Murphy, M., Bollen, E.L.E.M., Buckley, B.M., Cobbe, S.M., et al. (2002) Pravastatin in Elderly Individuals at Risk of Vascular Disease (PROSPER): A Randomized Controlled Trial. Lancet, 360, 1623-1630. http://dx.doi.org/10.1016/S0140-6736(02)11600-X

[45] Law, M. and Rudnicka, A. (2006) Statin Safety: A Systematic Review. American Journal of Cardiology, 97, S52-S60. http://dx.doi.org/10.1016/j.amjcard.2005.12.010

[46] Gladding, P., Pilmore, H. and Edwards, C. (2004) Potentially Fatal Interaction between Diltiazem and Statins. Annals of Internal Medicine, 140, W31.

[47] Onusko, E. (2008) Statins and Elevated Liver Tests: What's the Fuss? Even When Liver Function Tests Are Moderately Elevated, Statins Are Safe for Most Patients. Journal of Family Practice, 57, 449-452. 
Scientific Research Publishing (SCIRP) is one of the largest Open Access journal publishers. It is currently publishing more than 200 open access, online, peer-reviewed journals covering a wide range of academic disciplines. SCIRP serves the worldwide academic communities and contributes to the progress and application of science with its publication.

Other selected journals from SCIRP are listed as below. Submit your manuscript to us via either submit@scirp.org or Online Submission Portal.
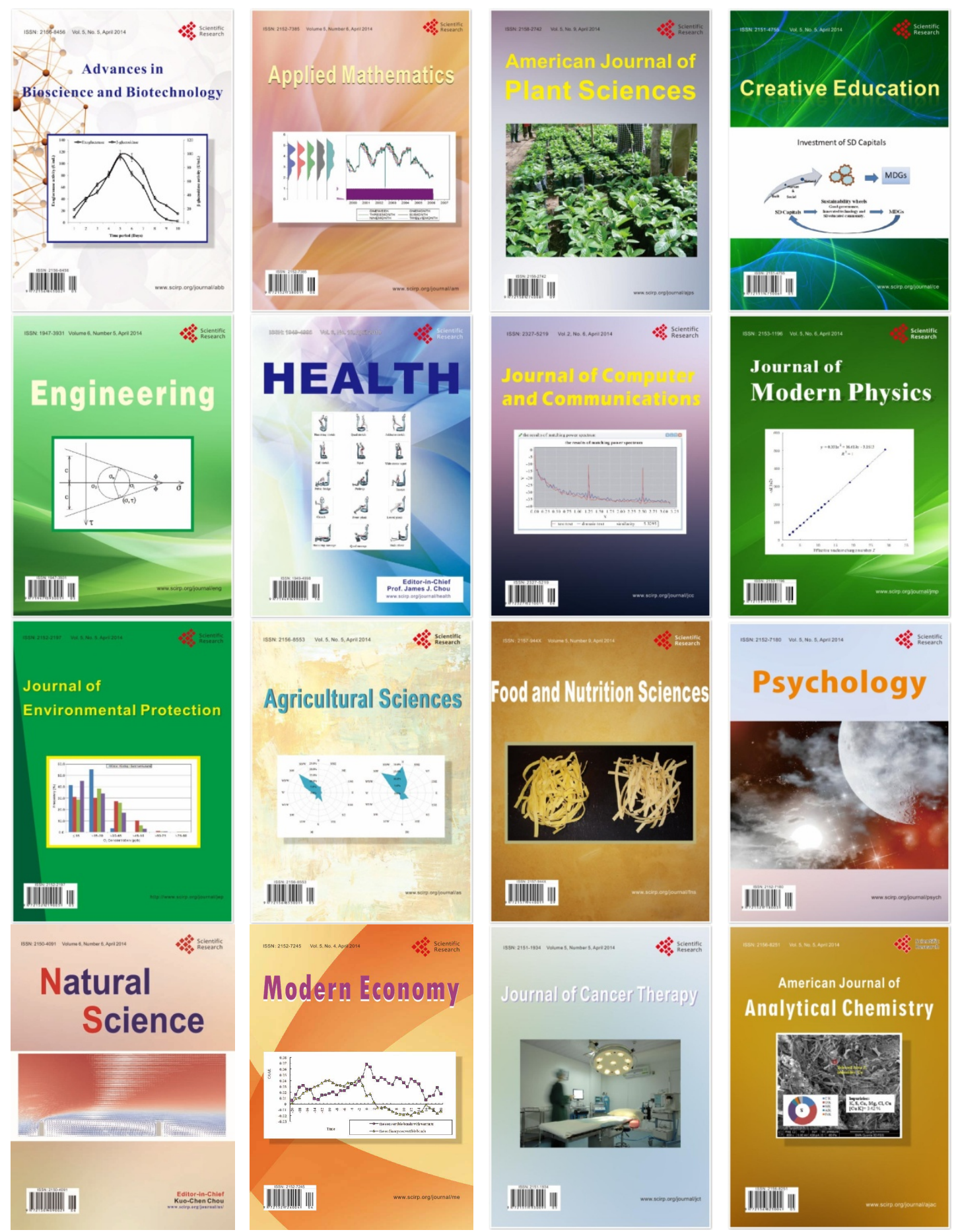